International Mathematical Forum, 2, 2007, no. 64, 3169 - 3180

\title{
Congestion in Stochastic DEA for Restructure Strategy: An Application to Iranian Commercial Banks
}

\author{
F. Hosseinzadeh Lotfi ${ }^{1}$ \\ Dept. of Mathematics, Science and Research Branch \\ Islamic Azad University, Tehran 14515-775, Iran \\ M. E. Mohammad Pourzarandi \\ Dept. of Industrial Management, Tehran Central Branch \\ Islamic Azad University, Tehran, Iran \\ M. Ahadzadeh Namin \\ Dept. of Mathematics, Science and Research Branch \\ Islamic Azad University, Tehran 14515-775, Iran \\ M. A. Jahantighey \\ Dept. of Mathematics, Islamic Azad University \\ Zaheden, Iran \\ Sh. Abolghasemzadeh \\ Dept. of Mathematics, Education \\ Tehran, Iran
}

\begin{abstract}
DEA (Data Envelopment Analysis) is a management science method that has been widely applied for performance analysis in various sectors. The application in this paper for treating congestion in DEA are extended by according them chance constrained programming formulations. A shortcoming of previous DEA applications is that it has been used to mainly evaluate ex ante performance.Congestion indicates an
\end{abstract}

\footnotetext{
${ }^{1}$ Corresponding author:Farhad Hosseinzadeh Lotfi, E-mail:hosseinzadeh_lotfi@yahoo.com
} 
economic state where inputs are overly invested. Evidence of congestion occurs whenever reducing some inputs can increase outputs. A congestion in stochastic DEA model is presented and then it is reformulated in the manner that the congestion in stochastic model incorporate future information. This research applies the approach to plan the restructure strategy of Iranian commercial banks.

Keywords: Linear Programming Problem, Data Envelopment Analysis (DEA), Stochastic, Standard Distribution, Standard Normal Distribution

\section{Introduction}

Congestion indicates an economic state where inputs are overly invested. Thus evidence of congestion occurs whenever reducing some input can increase outputs. Fare and Grosskopf(1983) first introduced an implementable from for analyzing congestion quantitatively. (1996)introduced an alternative DEA approach(CCT approach)for congestion study. DEA (Data Envelopment Analysis) is adecisional technique that has been widely used for performance analysis in public and private sectors. A variety of DEA applications, along with its conceptual and methodological developments, maybe for may decisive cases in the past two decades.

Believing that future planning is more important that past performance evaluation, this study documents how to incorporate future information into analytical framework of DEA, to attain the research objective, we use a stochastic DEA model. Cooper et al.(2002) treated the topic of stochastic characterizations of efficiency and inefficiency in DEA using chance constrained programing formulations snd constructs.

Congestion has been under researched topic in the economic theory of production even though it can be of importance when its use is associated whit need for augmenting inputs to serve important objectives based output maximization. As noted in Cooper et al.(2001), for instance, congestion is used in China to deal whit the need for providing employment for along labor force, with some 16,000,000 - 18,000,000 new entrants each year. In addition, as noted in Cooper et at.(2003), they described models for treating congestion in DEA are extended by according them chance constrained programing formulations. However, it is shown to be possible to avoid some of the need for dealing with these none-liner problems by identifying conditions under which they can be replaced by ordinary DEA models. This paper help our for perform this application. 


\section{Linear programing with stochastic variables}

To describe the analytical structure of our Lp models, we compair with a conventional Lp model and use as noted in Cooper et al. We have linear programing with stochastic variables as follow,

$$
\begin{array}{lll}
\min (\max ) & F(x)=\sum_{j=1}^{n} c_{j} x_{j} \\
\text { s.t. } & \operatorname{prob}\left\{\sum_{j=1}^{n} a_{i j} x_{j} \leq b_{i}\right\} \geq p_{i} & \\
& x_{j} \geq 0 & j=1, \ldots, m
\end{array}
$$

Suppose that $a_{i j}$ and $b_{i}, j=1, \ldots, n, i=1, \ldots, m$ are stochastic variables.

$$
\begin{array}{lll}
\min (\max ) & F(x)=\sum_{j=1}^{n} c_{j} x_{j} & \\
\text { s.t. } & \operatorname{prob}\left\{\sum_{j=1}^{n} \tilde{a_{i j}} x_{j} \leq \tilde{b_{i}}\right\} \geq p_{i} & i=1, \ldots, m \\
& x_{j} \geq 0 & j=1, \ldots, n
\end{array}
$$

Where the above two models are designed the $\operatorname{symbols}\left(\tilde{a_{i j}}, \tilde{b_{i}}\right)$ represent the stochastic variables, ' prob' stands for a probability and $p_{i}=1-\alpha_{i}$ stands for a probability that $\sum_{j=1}^{n} \tilde{a_{i j}} x_{j} \leq \tilde{b_{i}}$. Thus $\alpha_{i}$ is considered as a risk criterion representing his/her utility of a data. On the other hand, $p_{i}$ indicated the probability of attaining the requirement. The risk criterion $\left(\alpha_{i}\right)$ is also a prescribed value that is measured on the range between 0 and 1 . Suppose that $\tilde{a_{i j}}, j=1, \ldots, n, i=1, \ldots, m$ have standard distribution and $\operatorname{var}\left(\tilde{a_{i j}}\right)$ indicates the variance of $\tilde{a_{i j}}$ and $\mathrm{E}\left(\tilde{a_{i j}}\right)$ indicates the mean of $\tilde{a_{i j}}$. And $\tilde{b_{i}}, i=1, \ldots, m$ have standard distribution and $\operatorname{var}\left(\tilde{b}_{i}\right)$ indicates the variance of $\tilde{b}_{i}$ and $\mathrm{E}\left(\tilde{b}_{i}\right)$ indicates the mean of $\tilde{b}_{i}$. let

$$
h_{i}=\sum_{j=1}^{n} \tilde{a_{i j}} x_{j}-\tilde{b_{i}}=\sum_{j=1}^{n+1} \tilde{a_{i j}} x_{j}, i=1, \ldots, m
$$

and $x_{n+1}=1, a_{i n+1}=-\tilde{b}_{i}, \quad i=1, \ldots, m$

Denote that $h_{i}$ is stochastic variables with standard distribution. Then we have

$$
\begin{aligned}
& E\left(h_{i}\right)=E\left(\sum_{j=1}^{n} \tilde{a_{i j}} x_{j}-\tilde{b_{i}}\right)=\sum_{j=1}^{n+1} E\left(\tilde{a_{i j}}\right) x_{j}=\sum_{j=1}^{n} E\left(\tilde{a_{i j}}\right) x_{j}-E\left(\tilde{b_{i}}\right) \\
& i=1, \ldots, m
\end{aligned}
$$

and $\operatorname{var}\left(h_{i}\right)=X^{T} D_{i} X$ where $X=\left(x_{1}, \ldots, x_{n}, 1\right)^{T}$ and 


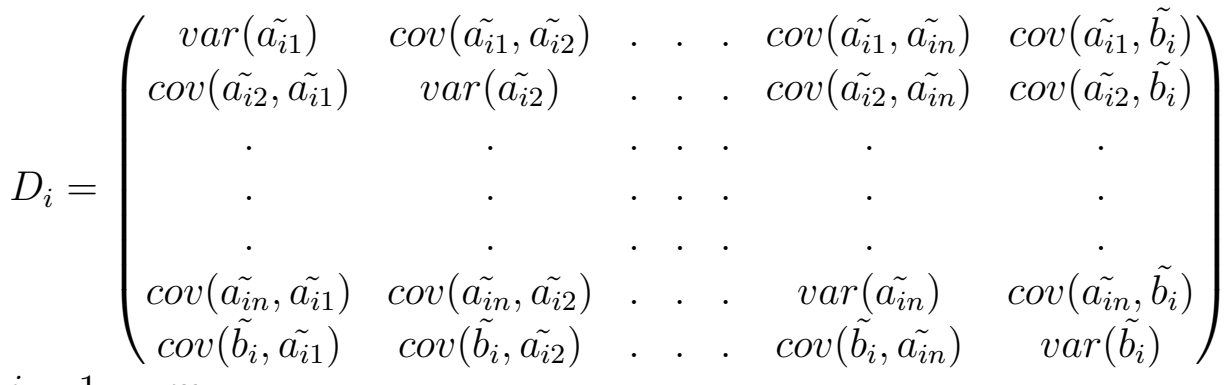

$i=1, \ldots, m$

Therefore, $\operatorname{prob}\left\{h_{i} \leq 0\right\} \geq p_{i}, i=1, \ldots, m$

Which follow the standard normal distribution which zero mean and unit variance.

$$
\operatorname{prob}\left\{\frac{h_{i}-E\left(h_{i}\right)}{\sqrt{\operatorname{var}\left(h_{i}\right)}} \leq \frac{-E\left(h_{i}\right)}{\sqrt{\operatorname{var}\left(h_{i}\right)}}\right\} \geq p_{i}, \quad i=1, \ldots, m
$$

Since $\frac{h_{i}-E\left(h_{i}\right)}{\sqrt{\operatorname{var}\left(h_{i}\right)}}$ follows the standard normal distributed the invertibility of Eq. (1)is executed as follow

$$
\Phi\left(\frac{-E\left(h_{i}\right)}{\sqrt{\operatorname{var}\left(h_{i}\right)}}\right) \geq \Phi\left(c_{i}\right)=p_{i}, \quad i=1, \ldots, m
$$

Hear $\Phi$ stands for a cumulative distribution the normal distribution and $\Phi^{-1}$ indicates its inverse function.

Therefore we have

Or

$$
\begin{aligned}
& \frac{-E\left(h_{i}\right)}{\sqrt{\operatorname{var}\left(h_{i}\right)}} \geq c_{i}, \quad i=1, \ldots, m \\
& E\left(h_{i}\right)+c_{i} \sqrt{\operatorname{var}\left(h_{i}\right)} \leq 0
\end{aligned}
$$

$$
\sum_{j=1}^{n} E\left(\tilde{a_{i j}}\right) x_{j}-E\left(\tilde{b_{i}}\right)-c_{i} \sqrt{\operatorname{var}\left(h_{i}\right)} \leq 0, \quad i=1, \ldots, m
$$

Then we have the following linear programing model with decisive variables.

$$
\begin{array}{lll}
\min (\max ) & F(x)=\sum_{j=1}^{n} c_{j} x_{j} \\
\text { s.t. } & \sum_{j=1}^{n} E\left(\tilde{a_{i j}}\right) x_{j}-E\left(\tilde{b_{i}}\right)-c_{i} \sqrt{\operatorname{var}\left(h_{i}\right)} \leq 0 & , \quad i=1, \ldots, m \\
& x_{j} \geq 0 & j=1, \ldots, n
\end{array}
$$




\section{Stochastic DEA models}

To describe the proposed Stochastic DEA models, we tell a summary paper of Cooper at et.(2003). This study assumes that there are $\mathrm{n}, \operatorname{DMUs}(j=1, \ldots, n)$ and $\tilde{X}_{j}=\left(\tilde{x_{1 j}}, \ldots, \tilde{x}_{m j}\right)^{T}$ and $\tilde{Y}_{j}=\left(\tilde{y_{1 j}}, \ldots, \tilde{y_{s j}}\right)^{T}$ random input and output vector of each $D M U_{j}, \quad j=1, \ldots, n$ and $X_{j}=\left(x_{1 j}, \ldots, x_{m j}\right)$ and $Y_{j}=\left(y_{1 j}, \ldots, y_{s j}\right)$ stand for corresponding vectors of expected values of input and output for each $D M U_{j}, \quad j=1, \ldots, n$.

It is important to note that this study is interested in future planning where we can control the quantity of inputs as our decision variables, whilst being unable to control outputs, because these quantities depend upon external factors such as an economic condition, a demographic change, and other socioeconomic factors that influence the magnitude of outputs. Hence, the inputs are considered as deterministic variables and the outputs are considered as stochastic variables.

Let us consider all input and output components to be jointly normally distributed in the follow chance constrained version of a Stochastic DEA models.

$$
\begin{array}{lll}
\max & \phi \\
\text { s.t. } & p\left\{\sum_{j=1}^{n} \tilde{y_{i j}} \lambda_{j} \geq \phi \tilde{y_{i o}}\right\} \geq 1-\alpha \quad r=1, \ldots, s \\
& p\left\{\sum_{j=1}^{n} \tilde{x_{i j}} \lambda_{j} \leq \tilde{x_{i o}}\right\} \geq 1-\alpha \quad i=1, \ldots, m \\
& \sum_{j=1}^{n} \lambda_{j}=1 & \\
& \lambda_{j} \geq 0 & j=1, \ldots, n
\end{array}
$$

Where the above model model, p means "probability" and $\alpha$ is a predetermined number between ) and 1 .

Definition 1( stochastic Efficiency): $D M U_{o}$ is stochastic efficient if anf only if the follow conditions are both satisfied.

$1-\phi^{*}=1$

2- Slack values are all zeros for all optimal solution.

Suppose that $\delta_{r} \geq 0$ and $\xi_{i} \geq 0$ used as the external slack for rth output and ith input chance constrain satisfies

$$
p\left\{\sum_{j=1}^{n} \tilde{y_{i j}} \lambda_{j}-\Phi \tilde{y_{i o}} \geq 0\right\}=(1-\alpha)+\delta_{r}, \quad r=1, \ldots, s
$$


and

$$
p\left\{\sum_{j=1}^{n} \tilde{x_{i j}} \lambda_{j}-\tilde{x_{i o}}\right\}=(1-\alpha)+\xi_{i}, \quad i=1, \ldots, m
$$

then there must exist posetive number $s_{r}^{+} \geq 0$ and $s_{i}^{-} \geq 0$ such that

and

$$
p\left\{\sum_{j=1}^{n} \tilde{y_{i j}} \lambda_{j}-\Phi \tilde{y_{i o}} \geq s_{r}^{+}\right\}=1-\alpha, \quad r=1, \ldots, s
$$

$$
p\left\{\sum_{j=1}^{n} \tilde{x_{i j}} \lambda_{j}+s_{i}^{-} \leq \tilde{x_{i o}}\right\}=1-\alpha, \quad i=1, \ldots, m
$$

Therefore we have the following stochastic version of the BCC model

$$
\begin{array}{lll}
\max & \phi+\epsilon\left(\sum_{r=1}^{s} s_{r}^{+}+\sum_{i=1}^{m} \tilde{s_{i}^{-}}\right) & \\
\text {s.t. } & p\left\{\sum_{j=1}^{n} \tilde{y_{i j}} \lambda_{j}-\phi \tilde{y_{i o}} \geq \tilde{s}_{r}^{+}\right\}=1-\alpha & r=1, \ldots, s \\
& p\left\{\sum_{j=1}^{n} \tilde{x_{i j}} \lambda_{j}+s_{i}^{-} \leq \tilde{x_{i o}}\right\}=1-\alpha & \\
& \sum_{j=1}^{n} \lambda_{j}=1 & \\
& \lambda_{j} \geq 0, s_{i}^{-} \geq 0, s_{r}^{+} \geq 0, \quad i=1, \ldots, m, r=1, \ldots, s, \quad j=1, \ldots, n
\end{array}
$$

In similar manner, it is natural to generalize the " one model" approach to congestion represented in paper of Cooper et at.(2003) to the follow stochastic version:

$$
\begin{array}{lll}
\max & \phi+\epsilon\left(\sum_{r=1}^{s} s_{r}^{+}-\epsilon \sum_{i=1}^{m} s_{i}^{-}\right) & \\
\text {s.t. } & p\left\{\sum_{j=1}^{n} \tilde{y_{i j}} \lambda_{j}-\phi \tilde{y_{i o}} \geq s_{r}^{+}\right\}=1-\alpha & r=1, \ldots, s \\
& p\left\{\sum_{j=1}^{n} \tilde{x_{i j}} \lambda_{j}+s_{i}^{-} \leq \tilde{x_{i o}}\right\}=1-\alpha & \\
& \sum_{j=1}^{n} \lambda_{j}=1 & \\
& \lambda_{j} \geq 0, s_{i}^{-} \geq 0, s_{r}^{+} \geq 0, \quad i=1, \ldots, m, r=1, \ldots, s, \quad j=1, \ldots, n
\end{array}
$$


It is easy to see section(2), with normal distribution and zero order decision rules we can obtain a deterministic equivalent for (3.5)and(3.6) as follows,

$$
\begin{array}{lll}
\max & \phi+\epsilon\left(\sum_{r=1}^{s} s_{r}^{+}+\sum_{i=1}^{m} s_{i}^{-}\right) & \\
\text {s.t. } & \phi y_{r o}-\sum_{j=1}^{n} y_{r j} \lambda_{j}+s_{r}^{+}-\Phi^{-1}(\alpha) \sigma_{r}^{o}(\phi, \alpha)=0 & r=1, \ldots, s \\
& \sum_{j=1}^{n} x_{i j} \lambda_{j}+s_{i}^{-}-\Phi^{-1}(\alpha) \sigma_{i}^{I}(\alpha)=x_{i o} & i=1, \ldots, m \\
& \sum_{j=1}^{n} \lambda_{j}=1 & \\
& \lambda_{j} \geq 0, s_{i}^{-} \geq 0, s_{r}^{+} \geq 0, \quad i=1, \ldots, m, r=1, \ldots, s, \quad j=1, \ldots, n
\end{array}
$$

similarly, the equivalent of (3.6) can be represented by:

$$
\begin{array}{lll}
\max & \phi+\epsilon\left(\sum_{r=1}^{s} s_{r}^{+}-\epsilon \sum_{i=1}^{m} s_{i}^{-c}\right) & \\
\text { s.t. } & \phi y_{r o}-\sum_{j=1}^{n} y_{r j} \lambda_{j}+s_{r}^{+}-\Phi^{-1}(\alpha) \sigma_{r}^{o}(\phi, \alpha)=0 & r=1, \ldots, s \\
& \sum_{j=1}^{n} x_{i j} \lambda_{j}+s_{i}^{-c}-\Phi^{-1}(\alpha) \sigma_{i}^{I}(\alpha)=x_{i o} & i=1, \ldots, m \\
& \sum_{j=1}^{n} \lambda_{j}=1 & \\
& \lambda_{j} \geq 0, s_{i}^{-} \geq 0, s_{r}^{+} \geq 0, \quad i=1, \ldots, m, r=1, \ldots, s, \quad j=1, \ldots, n
\end{array}
$$

There $\Phi$ is the standard normal distribution function and $\Phi^{-1}$, its inverse. Finally

$$
\begin{aligned}
& \left(\sigma_{r}^{o}(\phi, \alpha)\right)^{2}=\sum_{i \neq o} \sum_{j \neq o} \lambda_{i} \lambda_{j} \operatorname{cov}\left(\tilde{y_{r i}}, \tilde{y_{r j}}\right)+2\left(\lambda_{o}-\phi\right) \sum_{i \neq o} \lambda_{i} \operatorname{cov}\left(\tilde{y_{r i}}, \tilde{y_{r o}}\right)+\left(\lambda_{o}-\right. \\
& \phi)^{2} \operatorname{var}\left(\tilde{y_{r o}}\right) \\
& \text { and }
\end{aligned}
$$


$\left(\sigma_{i}^{I}(\alpha)\right)^{2}=\sum_{j \neq o} \sum_{k \neq o} \lambda_{j} \lambda_{k} \operatorname{cov}\left(\tilde{x_{i j}}, \tilde{x_{i k}}\right)+2\left(\lambda_{o}-\phi\right) \sum_{j \neq o} \lambda_{j} \operatorname{cov}\left(\tilde{x_{i j}}, \tilde{x_{i o}}\right)+\left(\lambda_{o}-\phi\right)^{2} \operatorname{var}\left(\tilde{x_{i o}}\right)$

Theorem 1: Congestion is present for $D N U_{o}$ to the prescribed level of probability in stochastic model (3.7)if and only if for an optimal solution $\left(\varphi^{*}, \lambda^{*}, s^{+^{*}}, s^{-c^{*}}\right)$ of $(3.8)$, there exists at least one $s^{-c^{*}}>0\left(1 \leq i_{o} \leq m\right)$.

\section{An application of Stochastic DEA models}

In this section, we consider five Iranian banks with two inputs and two outputs stochastic data. In this research $\tilde{X}_{1}$ is "payable profit ", $\tilde{X}_{2}$ is " personnel ", $\tilde{Y}_{1}$ is " facilities " and $\tilde{Y}_{2}$ is "Received profit " of bank. Cause to inputs and outputs are Stochastic with normal distribution, we have mean and variance of inputs and outputs as follows,

Table 1: mean of payable profit and personnel

\begin{tabular}{|c|c|c|c|c|c|}
\hline$E\left(x_{i j}\right)$ & 1 & 2 & 3 & 4 & 5 \\
\hline$E\left(X_{1 j}\right)$ & 6214.705 & 4937.711667 & 16264.77 & 3187.220417 & 10992.61042 \\
\hline$E\left(X_{2 j}\right)$ & 13.14541667 & 12.4275 & 13.86875 & 16.50333333 & 11.88416667 \\
\hline
\end{tabular}

Table 2: Mean of facilities and Received profit

\begin{tabular}{|c|c|c|c|c|c|}
\hline$E\left(y_{r j}\right)$ & 1 & 2 & 3 & 4 & 5 \\
\hline$E\left(Y_{1 j}\right)$ & 282125.6522 & 180786.773 & 271150.0161 & 855475.1522 & 862602.4452 \\
\hline$E\left(Y_{2 j}\right)$ & 40742.8 & 9441.136522 & 16774.19652 & 84894.71217 & 157820.9539 \\
\hline
\end{tabular}

Table 3: variance of inputs(payable profit and personnel)

\begin{tabular}{|c|c|c|c|c|c|}
\hline $\operatorname{var}\left(x_{i j}\right)$ & 1 & 2 & 3 & 4 & 5 \\
\hline $\operatorname{vae}\left(X_{1 j}\right)$ & 61775357.94 & 37810008.77 & 28165380.94 & 18474675.91 & 180617623.7 \\
\hline $\operatorname{var}\left(X_{2 j}\right)$ & 112.28729547 & 1.92682253 & 4.082228804 & 6.487875362 & 3.073938406 \\
\hline
\end{tabular}

Table 4: Variance of outputs(facilities and Received profit)

\begin{tabular}{|c|c|c|c|c|c|}
\hline $\operatorname{var}\left(y_{r j}\right)$ & 1 & 2 & 3 & 4 & 5 \\
\hline$E\left(Y_{1 j}\right)$ & 10438342998 & 1157943092 & 901499969.9 & 15248173088 & 46223196999 \\
\hline $\operatorname{var}\left(Y_{2 j}\right)$ & 319349741.2 & 102193533.9 & 336854494.1 & 9055718955 & 31520733945 \\
\hline
\end{tabular}


We can deterministic covariance of inputs and covariance of outputs that need in model(3-8) and(3-9). Showing in table $(5,6,7,8)$ as following.

Table 5: $\operatorname{cov}(X 1, X 1)$

\begin{tabular}{|c|c|c|c|c|c|}
\hline $\operatorname{cov}\left(x_{1 j}, x_{1 j}\right)$ & $x_{11}$ & $x_{12}$ & $x_{13}$ & $x_{14}$ & $x_{15}$ \\
\hline$x_{11}$ & 59201384.69 & 46273169.87 & 39947161.84 & 32328417.12 & 104738576.3 \\
\hline$x_{12}$ & 46273169.87 & 36234591.73 & 31254093.77 & 25257222.19 & 82060967.48 \\
\hline$x_{13}$ & 39947161.84 & 31254093.77 & 26991823.4 & 21840390.15 & 70772451.89 \\
\hline$x_{14}$ & 32328417.12 & 25257222.19 & 21840390.15 & 17704897.74 & 57179560.38 \\
\hline$x_{15}$ & 104738576.3 & 82060967.48 & 70772451.89 & 57179560.38 & 185942039.4 \\
\hline
\end{tabular}

Table 6: $\operatorname{cov}(X 2, X 2)$

\begin{tabular}{|c|c|c|c|c|c|}
\hline $\operatorname{cov}\left(x_{2 j}, x_{2 j}\right)$ & $x_{21}$ & $x_{22}$ & $x_{23}$ & $x_{24}$ & $x_{25}$ \\
\hline$x_{21}$ & 11.77532483 & 1.199621875 & 1.519594271 & 1.272698611 & 1.574231597 \\
\hline$x_{22}$ & 1.199621875 & 1.769602083 & 2.563776042 & 2.581629167 & 2.21150625 \\
\hline$x_{23}$ & 1.519594271 & 2.563776042 & 3.912135938 & 4.3734625 & 3.279776042 \\
\hline$x_{24}$ & 1.272698611 & 2.581629167 & 4.3734625 & 6.217547222 & 3.357298611 \\
\hline$x_{25}$ & 1.574231597 & 2.21150625 & 3.279776042 & 3.357298611 & 2.945857639 \\
\hline
\end{tabular}

Table 7: $\operatorname{cov}(Y 1, Y 1)$

\begin{tabular}{|c|c|c|c|c|c|}
\hline $\operatorname{cov}\left(y_{1 j}, y_{1 j}\right)$ & $y_{11}$ & $y_{12}$ & $y_{13}$ & $y_{14}$ & $y_{15}$ \\
\hline$y_{11}$ & 9984501998 & -2480925023 & -1065092995 & -3200565967 & -4415922686 \\
\hline$y_{12}$ & -2480925023 & 1107597740 & 552393950.1 & 2072749896 & 2454473916 \\
\hline$y_{13}$ & -1065092995 & 552393950.1 & 862304319 & 3142740309 & 4426989120 \\
\hline$y_{14}$ & -3200565967 & 2072749896 & 3142740309 & 14585209041 & 21495611751 \\
\hline$y_{15}$ & -4415922686 & 2454473916 & 4426989120 & 21495611751 & 44213492781 \\
\hline
\end{tabular}

Table 8: $\operatorname{cov}(Y 2, Y 2)$

\begin{tabular}{|c|c|c|c|c|c|}
\hline $\operatorname{cov}\left(y_{2 j}, y_{2 j}\right)$ & $y_{21}$ & $y_{22}$ & $y_{23}$ & $y_{24}$ & $y_{25}$ \\
\hline$y_{21}$ & 305464969.9 & 165211140.2 & 1628811015 & 1571499966 & 2921229784 \\
\hline$y_{22}$ & 165211140.2 & 97750336.75 & 175234655.6 & 878611276.7 & 3063433415 \\
\hline$y_{23}$ & 303300327 & 175234655.6 & 322208646.5 & 1646401317 & 3063433415 \\
\hline$y_{24}$ & 1571499966 & 878611276.7 & 1646401317 & 8661992044 & 16151354522 \\
\hline$y_{25}$ & 2921229784 & 1628811015 & 3063433415 & 16151354522 & 30150267252 \\
\hline
\end{tabular}

The Iranian banks have been long the strong protection of the Iranians government. A main rationale to support the government bank was to provide consumers with a stable and reliable facilities and Received profit(supply) that was long needed for Ibanks development, economic advancement and congestion. 
The results of efficient and congestion are shown in table 9:

Table 9: efficient and congestion of DMUs

\begin{tabular}{|c|c|c|c|}
\hline$D M U_{j}$ & Efficiency & Congestion in $I_{1}$ & Congestion in $I_{2}$ \\
\hline 1 & 1 & 0 & 0 \\
\hline 2 & 0.23317 & 45041.1 & 0 \\
\hline 3 & 0.309233 & 0 & 0 \\
\hline 4 & 1 & 0 & 0 \\
\hline 5 & 1 & 0 & 0 \\
\hline
\end{tabular}

Table (9) shows that $D M U_{1}, D M U_{4}$ and $D M U_{5}$ is efficient and do not have congestion, $D M U_{2}$ is not efficient and have congestion, $D M U_{3}$ is not efficient and do not have congestion.

\section{Conclusion}

The existing data envelopment analysis (DEA) models for measuring the relative efficiencies of a set of decision making units (DMUs) using various inputs to produce various outputs are limited to crisp data. The measure of efficiencies with stochastic inputs and outputs has been developed in this text. One of inefficiency factors, can be of importance when its use is associated with a need for augmenting inputs to serve important objectives besides output maximization is called congestion. It has been considered that we have based applicated example with the help of basic models with stochastic inputs and outputs. Evidently, this model have accounting complexity(nonlinear programing) for developing DEA models with stochastic data, you can do new research, to develop DEA models with stochastic data, for example you can determined stochastic return to scale.

\section{References}

[1] Allen, F., Broswell, M., Rao, P.V., 1972.Distribution free approximations for chance constraints. Operations Research 22, 610-621.

[2] Charnes, A., Cooper, W.W., Rhodes, E., 1981.Evaluating program and managerial efficiency: An application of data envelopment analysis to program follow through. Management Science 27, 668-697.

[3] Charnes, A., Cooper, W.W., Symonds, G.H., 1958. Cost horizons and certainty equivalents: An approach to stochastic programming of heating oil. Management Science 4, 235-263. 
[4] Charnes, A., Cooper, W.W., Thrall, R.M., 1991.A structure for classifying and characterizing efficiencies and inefficiencies in data envelopment analysis. Journal of Productivity Analysis 2, 197-237.

[5] Charnes, A., Cooper, W.W., Thrall, R.M., 1986.Identifying and classifying efficiencies and inefficiencies in data envelopment analysis. Operations Research Letters 5, 105-116.

[6] Charnes, A., Haag, S., Jaska, P., Semple, J., 1992. Sensitivity of efficiency classifications in the additive model of data envelopment analysis. International Journal of Systems Science 23, 789-798.

[7] Charnes, A., Neralic, L., 1990.Sensitivity analysis of the additive model in data envelopment analysis. European Journal of Operational Research 48, 332-341.

[8] Cooper, W.W., Gu, B., Li, S., 2001.Note: Alternative treatments of congestion - A response to the Cherchye, Kuosmanen and Post critique. European Journal of Operational Research 132, 85-87.

[9] Cooper, W.W., Deng, H., Gu, B., Li, S., Thrall, R.M., 2001.Using DEA to improve the management of congestion in Chinese industries (1981?1997). Socio-Economic Planning Sciences 35, 1-16.

[10] Cooper, W.W., Li, S., Seiford, L.M., Tone, K., Thrall, R.M., Zhu, J., 2001.Sensitivity and stability analysis in DEA: Some recent developments. Journal of Productivity Analysis 15, 217-246.

[11] Cooper, W.W., Deng, H., Huang, Z.M., Li, S.X., 2002. Change constrined programming approaches to technical efficiencies and inefficiencies in stochastic data envelopment analysis. Journal of the Operational Research Society $53,1347-1356$.

[12] Cooper, W.W., Deng, H., Huang, Z.M., Li, S.X., 2002. A one model approach to congestion in data envelopment analysis. Socio-Economic Planning Sciences 36, 231-238.

[13] Cooper, W.W., Huang, Z., Li, S., 1996a.Satisficing DEA models under chance constraints. The Annals of Operations Research 66, 279-295.

[14] Cooper, W.W., Thompson, R.G., Thrall, R.M., 1996b. Introduction: Ex- 
tensions and new developments in DEA. The Annals of Operations Research $66,3-46$.

[15] William W. Cooper, H. Deng, Zhimin Huang, Sus X.Li, 2003. Chance Constrained programming approaches to congestion in stochastic data envelopment analysis. European Journal of Operational Research.

Received: July 19, 2007 